\title{
Seasonal velocities of eight major marine-terminating outlet glaciers of the Greenland ice sheet from continuous in situ GPS instruments
}

\author{
A. P. Ahlstrøm ${ }^{1}$, S. B. Andersen ${ }^{1}$, M. L. Andersen ${ }^{1}$, H. Machguth ${ }^{1}$, F. M. Nick ${ }^{2,3}$, I. Joughin ${ }^{4}$, \\ C. H. Reijmer ${ }^{3}$, R. S. W. van de Wal ${ }^{3}$, J. P. Merryman Boncori ${ }^{5}$, J. E. Box ${ }^{1,6}$, M. Citterio ${ }^{1}$, D. van As ${ }^{1}$, \\ R. S. Fausto ${ }^{1}$, and A. Hubbard ${ }^{7}$ \\ ${ }^{1}$ Geological Survey of Denmark and Greenland, Øster Voldgade 10, 1350 Copenhagen, Denmark \\ ${ }^{2}$ Laboratoire de Glaciologie, Université libre de Bruxelles, Brussels, Belgium \\ ${ }^{3}$ Institute for Marine and Atmospheric research Utrecht, Utrecht University, Utrecht, the Netherlands \\ ${ }^{4}$ Applied Physics Laboratory, University of Washington, Seattle, USA \\ ${ }^{5}$ National Space Institute, Danish Technical University, Kgs. Lyngby, Denmark \\ ${ }^{6}$ Byrd Polar Research Center and Department of Geography, The Ohio State University, Columbus, USA \\ ${ }^{7}$ Institute of Geography \& Earth Sciences, Aberystwyth University, Aberystwyth, UK
}

Correspondence to: A. P. Ahlstrøm (apa@geus.dk)

Received: 1 August 2012 - Published in Earth Syst. Sci. Data Discuss.: 23 January 2013

Revised: 16 June 2013 - Accepted: 18 June 2013 - Published: 30 July 2013

\begin{abstract}
We present 17 velocity records derived from in situ stand-alone single-frequency Global Positioning System (GPS) receivers placed on eight marine-terminating ice sheet outlet glaciers in South, West and North Greenland, covering varying parts of the period summer 2009 to summer 2012. Common to all the observed glacier velocity records is a pronounced seasonal variation, with an early melt season maximum generally followed by a rapid mid-melt season deceleration. The GPS-derived velocities are compared to velocities derived from radar satellite imagery over six of the glaciers to illustrate the potential of the GPS data for validation purposes. Three different velocity map products are evaluated, based on ALOS/PALSAR data, TerraSAR$\mathrm{X} /$ Tandem- $\mathrm{X}$ data and an aggregate winter TerraSAR-X data set. The velocity maps derived from TerraSAR$\mathrm{X} /$ Tandem-X data have a mean difference of $1.5 \%$ compared to the mean GPS velocity over the corresponding period, while velocity maps derived from ALOS/PALSAR data have a mean difference of $9.7 \%$. The velocity maps derived from the aggregate winter TerraSAR-X data set have a mean difference of $9.5 \%$ to the corresponding GPS velocities. The data are available from the GEUS repository at doi:10.5280/GEUS000001.
\end{abstract}

\section{Introduction}

Determining and understanding the current contribution to sea level rise from the Greenland ice sheet has become a priority of global concern as the impact of climate change on the ice sheet mass loss is becoming increasingly apparent (IPCC, 2007). Major uncertainties in our ability to predict the mass loss from the Greenland ice sheet persist, particularly when it comes to understanding the dynamic mass loss from calving outlet glaciers (Vieli and Nick, 2011; Price et al., 2011). Since the dynamic mass loss is believed to con- stitute roughly half the contribution to sea level rise from the Greenland ice sheet over the last decade (Van den Broeke et al., 2009) and appears to be highly variable with time (Andresen et al., 2011; Bevan et al., 2012; Bjørk et al., 2012), understanding this mechanism is of paramount importance to reduce the uncertainty in predicting the impact of future climate change on the Greenland ice sheet.

The increasing focus on the dynamic mass loss from the Greenland ice sheet has been driven by a combination of in situ observations and remote sensing analysis, documenting a fast and widespread retreat and acceleration of the outlet 
Table 1. Temporal coverage of the GPS data collected. Abbreviations and ID's refer to the map in Fig. 1. Geographical positions are listed in Tables 2 to 4 .

\begin{tabular}{lllll}
\hline Glacier & Abbrev. & ID & Start date & End date \\
\hline Sermilik Bræ & SML & GPS-1 & 31 Aug 2009 & 19 Jul 2010 \\
Sermilik Bræ & SML & GPS-2 & 31 Aug 2009 & 9 Aug 2011 \\
Sermilik Bræ & SML & GPS-3 & 31 Aug 2009 & 9 Aug 2011 \\
Kangiata Nunata Sermia & KNS & GPS-1 & 23 Jul 2010 & 25 Aug 2011 \\
Kangiata Nunata Sermia & KNS & GPS-2 & 24 Aug 2009 & 25 Aug 2011 \\
Kangiata Nunata Sermia & KNS & GPS-3 & 24 Aug 2009 & 25 Aug 2011 \\
Sermeq Avanarleq & AVA & GPS-1 & 17 Aug 2009 & 16 Aug 2010 \\
Rink Glacier & RNK & GPS-2 & 9 Aug 2009 & 12 Aug 2010 \\
Rink Glacier & RNK & GPS-29428 & 12 Aug 2010 & 15 Aug 2011 \\
Store Glacier & STO & GPS-4 & 17 Aug 2009 & 14 Aug 2010 \\
Store Glacier & STO & GPS-29430 & 7 Aug 2010 & 1 Jul 2012 \\
Upernavik Glacier & UPE & GPS-2 & 17 Aug 2009 & 28 Jul 2011 \\
Upernavik Glacier & UPE & GPS-3 & 17 Aug 2009 & 28 Jul 2011 \\
Upernavik Glacier & UPE & GPS-4 & 18 Aug 2009 & 28 Jul 2011 \\
Petermann Glacier & PET & GPS-29408 & 24 Jul 2011 & 29 Jun 2012 \\
Petermann Glacier & PET & GPS-29419_2011 & 26 Jul 2011 & 12 Nov 2011 \\
Petermann Glacier & PET & GPS-29419_2012 & 24 May 2012 & 27 Jun 2012 \\
Petermann Glacier & PET & GPS-29422 & 25 Jul 2011 & 30 Jun 2012 \\
Humboldt Glacier & HUM & GPS-29425 & 21 Jul 2011 & 2 Jul 2012 \\
\hline
\end{tabular}

glaciers of the Greenland ice sheet. Although recent advances in modelling calving outlet glaciers seem promising (Nick et al., 2012; Vieli and Nick, 2011), such studies require observational data to determine the physical mechanisms behind outlet glacier behaviour (Moon et al., 2012).

Estimates of current and recent mass loss from the Greenland ice sheet relies largely on remote sensing analysis, either of the gravitational changes (Rignot et al., 2011), uplift of the surrounding land (Bevis et al., 2012) or elevation change (Pritchard et al., 2009; Sørensen et al., 2011) or by the mass budget method, i.e. by deriving the individual parts of the Greenland ice sheet mass balance separately (Van den Broeke et al., 2009; Rignot et al., 2008). The mass budget method requires an understanding of the interaction of the Greenland ice sheet with the climate system as well as a wealth of observations, which in turn provides an improved capability to model future mass balance changes with more confidence.

The increased accuracy of the mass budget method has been facilitated partly by improved regional climate models (Ettema et al., 2010) and partly by the recent advances in producing large-scale velocity maps of the ice sheet surface using radar imagery (Joughin et al., 2010; Rignot and Kanangaratnam, 2006). These recent velocity maps cover almost the entire Greenland ice sheet, but are limited in their temporal coverage. Generally, they yield the mean velocity over the time between two image acquisitions which cannot be too far apart in time (Joughin, 2002). The maximum time between two images depends for example on the velocityderivation method and on the physical properties of the target, such as surface velocity and rate of change of ice/snow surface properties, but rarely exceeds 3-4 weeks. A series of velocity maps have been produced to observe the pattern of seasonal change (Joughin et al., 2008). Such techniques have also been applied to fast-moving glaciers such as Jakobshavn Isbrae (Joughin et al., 2012), but in the limited areas where sufficient satellite data are collected. Furthermore, presently operating satellites limit temporal resolution ( $>10$ days) so satellite remote sensing cannot provide the higher temporal coverage required to resolve the individual acceleration events occurring on the scale of days (van de Wal et al., 2008).

Attempts at deriving such information from time-lapse photography show great promise (Ahn and Box, 2010), but so far in situ observations from the glacier surface are still required to provide the detailed seasonal variation in outlet glacier velocity and to validate both photographic and satellite observations.

Here we present a total of 17 continuous velocity records from eight major marine-terminating outlet glaciers from the Greenland ice sheet derived from single-frequency standalone Global Positioning System (GPS) receivers placed on the glacier surface, covering varying parts of the period summer 2009 to summer 2012. We present data from a range of different types of marine-terminating outlet glaciers along the entire western flank of the Greenland ice sheet from the southern tip to the northern coast (see Table 1 and Fig. 1). The GPS-derived velocities are compared to velocities derived from radar satellite imagery over six of the glaciers, illustrating the potential of combining temporal and spatial velocity data. 


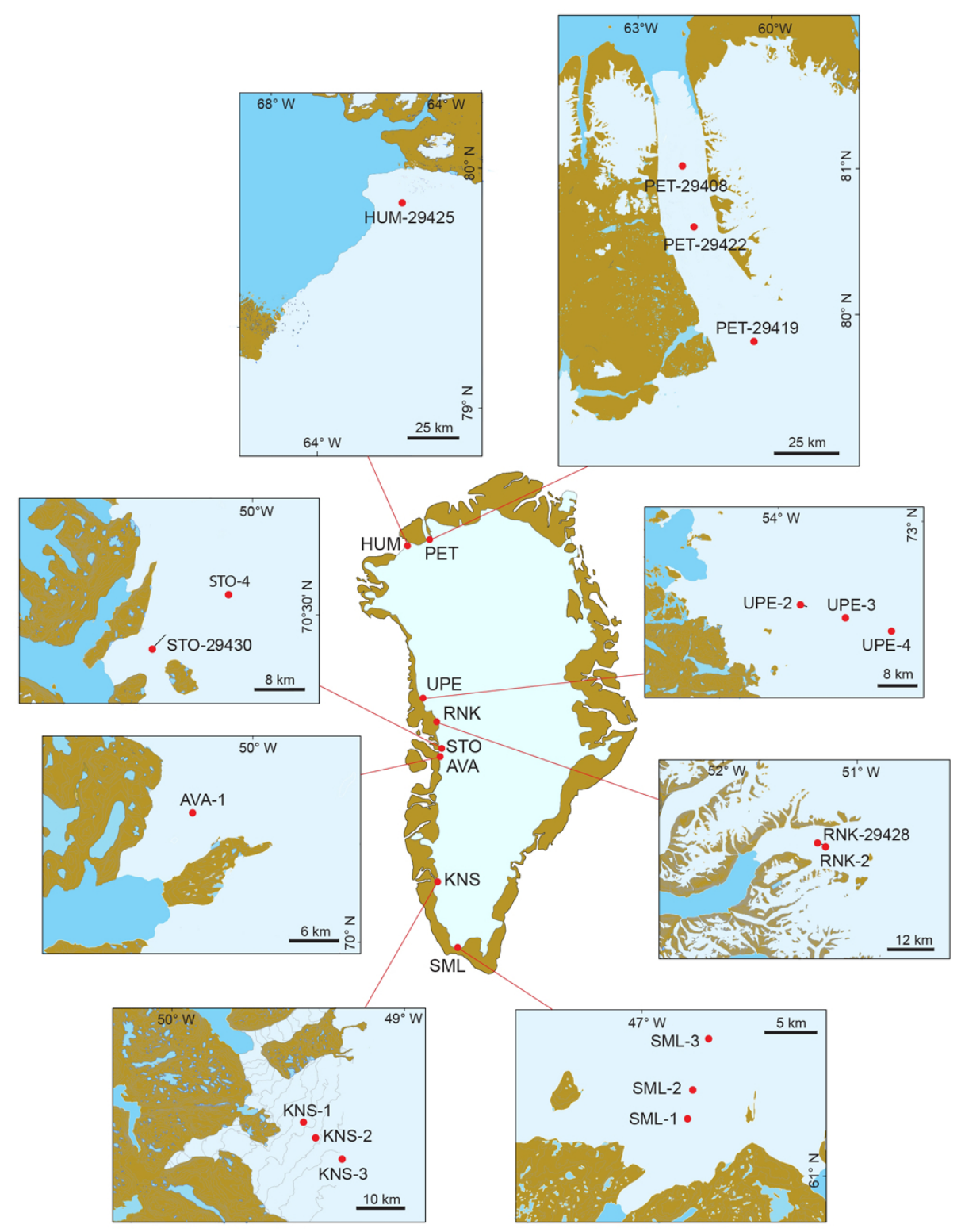

Figure 1. Map of locations, with inserts showing retrieval positions of GPS instruments on individual glaciers.

\section{Methods}

Figure 1 shows the glaciers studied, indicating the location of each of the GPS instruments at the time of retrieval or when the data series ended (in the case of transmitted data).

\subsection{Continuous GPS measurements}

The stand-alone single-frequency GPS receiver used in this study was developed at Institute for the Marine and Atmospheric research Utrecht, Utrecht University (IMAU) and first applied by Van de Wal et al. (2008) (see Fig. 2). The GPS receiver as well as the subsequent data processing particular to this system has previously been described in detail in Den Ouden et al. (2010) and further in Dunse et al. (2012). The GPS receiver is a single-frequency (L1 band) system that is designed for extended operation in harsh conditions with no maintenance at a low instrument cost. A later version includes ARGOS transmission capability, potentially alleviating part of the problem with loss of receivers.

The receiver is powered by a $3.6 \mathrm{~V}$ lithium battery that allows the unit to operate for more than one year at a power consumption of $15 \mathrm{Ah} \mathrm{yr}^{-1}$. To facilitate this, only time and position is stored in the data logger, meaning that it is not possible to perform corrections relying on phase carrier information, double differencing or between-satellite differencing that could otherwise improve the precision. Thus effects from ionospheric delay and inaccuracy in satellite orbital and 


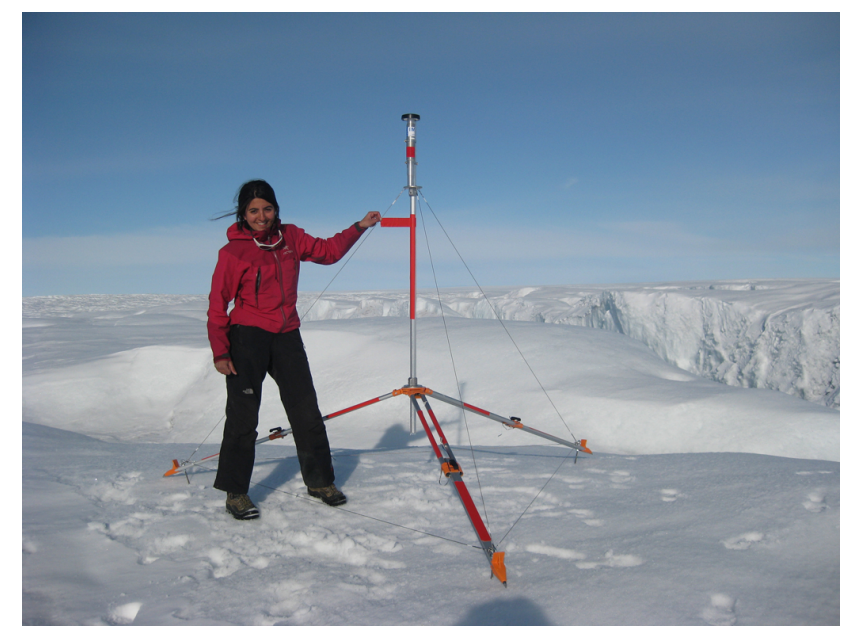

Figure 2. Deployment of a GPS instrument on KNS.

clock information will deteriorate the precision of the positional information stored, as no post-processing is possible. Only the multipath error is addressed by employing a patch antenna that minimizes signal reception from below. The estimated error of a single GPS measurement is on the order of 3-4 m, as derived from similar data from Svalbard (Den Ouden et al., 2010). The light-weight receivers can be fitted on a tripod or a stake drilled into the ice.

\subsection{Data processing}

The raw data consists of hourly (or once every third hour in the case of ARGOS-transmitted data) measurements of time and geographical position. To obtain meaningful results, a three-step processing approach is applied: first, outliers are removed, then the positions are averaged and finally the velocities derived from these positions are again averaged. This approach yields robust average velocities at the expense of temporal resolution.

In the first step, outliers are removed by comparing consecutive standard deviations of the latitudinal and longitudinal positions over a moving time window of $60 \mathrm{~h}$. If the difference between consecutive standard deviations is larger than a threshold of $0.2 \mathrm{~m}$, the record is excluded from further analysis. The time window length and threshold were chosen to yield robust velocities without excluding too many data records for all the glaciers measured. Only for Upernavik Glacier, a higher threshold value of $0.4 \mathrm{~m}$ was utilized, due to large data gaps in these records. The higher threshold ensures that at least some data is available for the subsequent steps in the procedure, even if the data quality is not of the same standard.

In the second step, the error in position is addressed by applying a running average to the latitudinal and longitudinal position, respectively, over a 7-day period $(168 \mathrm{~h})$ using a modified Welch window with an exponent of 8 This ef- fectively assigns less weight towards the centre of the window compared to the original Welch function described in e.g. Press et al. (1992), which has an exponent of 2. Dunse et al. (2012) similarly used a 7-day running average, yielding robust results by using a square window. Average positions are calculated if more than $95 \%$ of the records within a given time window are present, except for Upernavik Glacier, where only $50 \%$ are required due to numerous data gaps. Data gaps may occur due to either loss of power supply, poor satellite reception or logger memory failure. Subsequently, velocities are calculated as taking the distance between two average positions and dividing by the time interval. Finally, the third step is the application of a similar 7-day running average to the velocities derived from the averaged positions. As with all window-averaging methods, the resulting velocities are mid-point values.

Den Ouden et al. (2010) found a combined horizontal accuracy of this system of $1.62 \mathrm{~m}$ over the period 2006-2009 in central Spitsbergen. As the ionospheric effect changes over time and position, this result can only be indicative of the accuracy of the measurements presented here. Error analysis of similar GPS instruments in Greenland at $67^{\circ} \mathrm{N}$ show a combined horizontal accuracy of $2.1 \mathrm{~m}$ in 2010-2011 for hourly measurements of a fixed position, so slightly higher than the values in central Spitsbergen. The Greenland data yield a typical error of $5 \mathrm{~m} \mathrm{yr}^{-1}$, if 7-day running averages are considered. This $5 \mathrm{~m} \mathrm{yr}^{-1}$ is the standard deviation used in this study.

As discussed in Den Ouden et al. (2010) and Dunse et al. (2012), the presence of spurious oscillations in the processed time series cannot be excluded due to the noisy nature of the raw data and spectral leakage caused by the averaging procedure, as well as other unknown position or time-dependent error sources. Following Dunse et al. (2012), we only consider periodic fluctuations with amplitude over $30 \mathrm{~m} \mathrm{yr}^{-1}$.

\section{Results}

\subsection{GPS velocity data}

Placing GPS instruments on outlet glaciers implies taking a significant risk of losing the instruments. The glacier surface is typically highly crevassed and experiences significant melt and severe storms during the deployment period. In addition to this, the GPS moves closer to the front increasing the chance of losing the instrument into a crevasse. Retrieval is only possible by helicopter and inherently depends on the experience of the pilot. Even when the helicopter pilot has managed to land or hover in the vicinity of a GPS, it is not always possible to retrieve it. For these reasons, up to four GPS instruments were placed at various distances from the front of each glacier. Despite a large number of lost GPS instruments, it was possible to retrieve at least one GPS from each of the selected glaciers. To improve the data retrieval rate, 


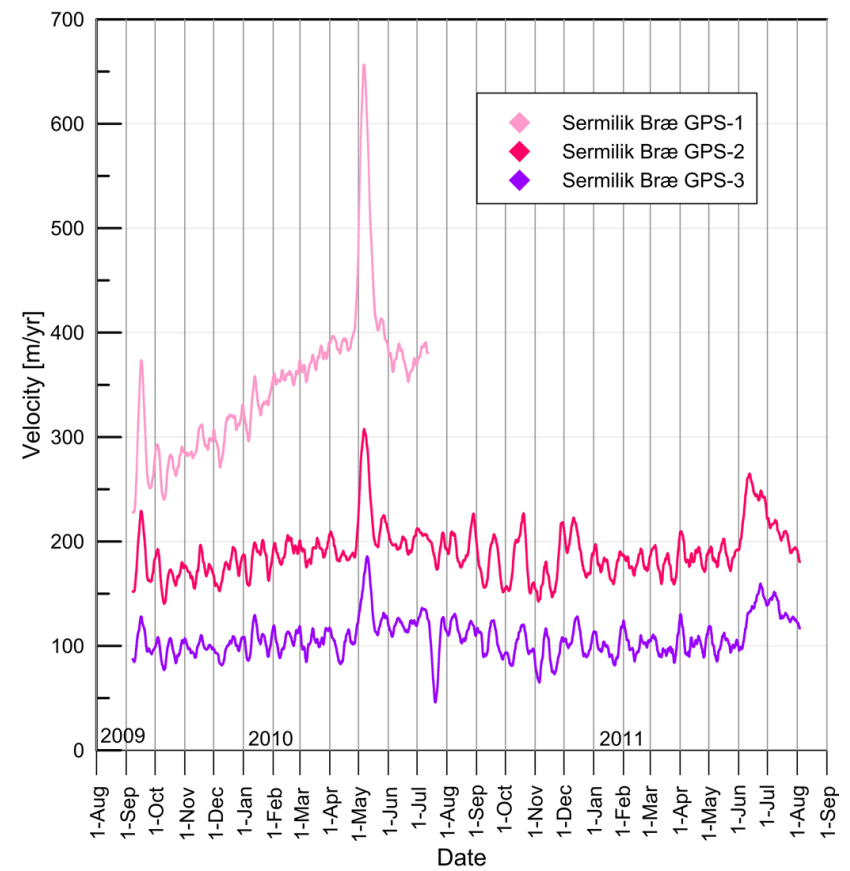

Figure 3. Sermilik Bræ 7-day averaged GPS velocities (see Fig. 1 and Table 1 for instrument position and operational period).

the later versions of the GPS instrument were equipped with an ARGOS transmission system. Other GPS instruments currently in use are equipped with Iridium modems for the same reason.

Data retrieval from the GPS receivers were generally successful with the exception of the Upernavik data, which were damaged during the logger extraction process, and the Petermann data from the uppermost GPS, which suffered from a transmission problem. The temporal coverage of the GPS data collected is listed in Table 1. The derived GPS velocities are shown in Figs. 3-10.

The GPS positions and velocities derived are available from the GEUS repository at doi:10.5280/GEUS000001 in the 7-day averaged version discussed in this work as well as in the original temporal resolution for the hourly data and every 6 hours for the ARGOS-transmitted data. Additional files are available containing the original raw input data.

\subsection{Comparison to satellite-derived velocities}

One of the useful aspects of in situ data is their use as ground control for the spatially extensive satellite products. Thus we compare the observed GPS velocities with velocities derived from satellite radar imagery. Three data sets were used for comparison:

1. Winter velocity maps (November 2009 to February 2010) at a $400 \mathrm{~m}$ spatial resolution that were produced by applying offset tracking to ALOS/PALSAR satellite radar imagery using SUSIE (Scripts and Utilities

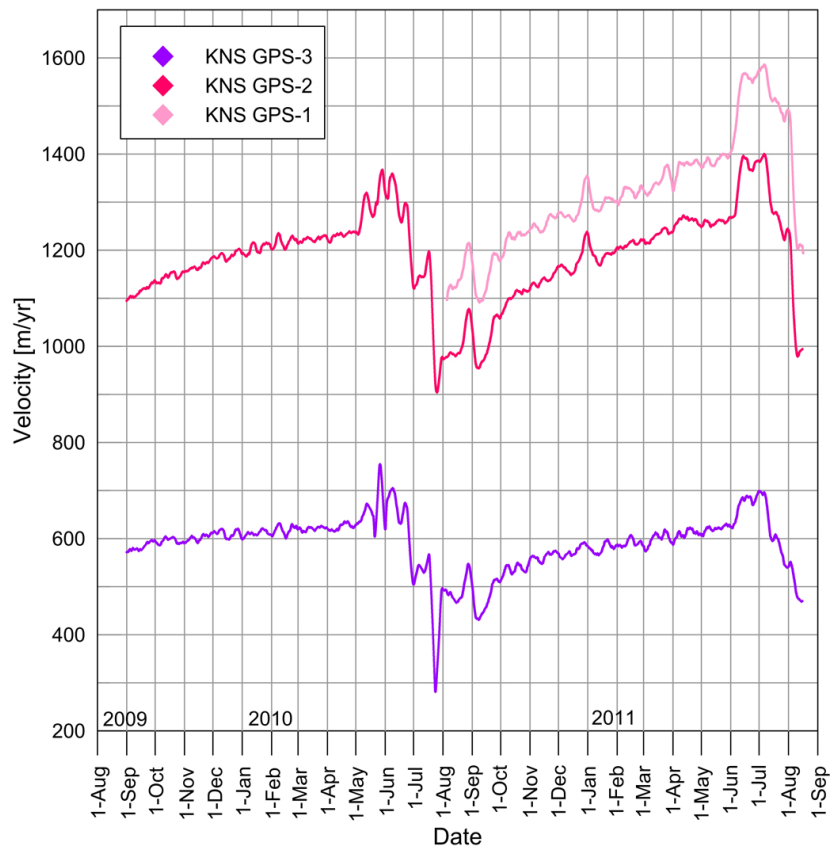

Figure 4. Kangiata Nunata Sermia 7-day averaged GPS velocities (see Fig. 1 and Table 1 for instrument position and operational period).

for SAR Ice-motion Estimation) (Merryman Boncori et al., 2010; Ahlstrøm et al., 2011), which is a processing chain based on the commercial software package distributed by GAMMA Remote Sensing.

2. An aggregate winter (November 2010 to April 2011) velocity map (Moon et al., 2012) at $400 \mathrm{~m}$ spatial resolution that was produced from combining available TerraSAR-X satellite radar imagery during this period, using well established speckle-tracking and interferometric methods (Joughin, 2002). The aggregate velocity map is thus combined by including several velocity maps (or sometimes just a single map).

3. Short period (11 days) and high resolution ( $100 \mathrm{~m}$ grid posting with a true resolution of ca. $300 \mathrm{~m}$ ) velocity maps derived from TerraSAR-X satellite radar imagery (Moon et al., 2012). The short-period TerraSAR-Xderived data cover all seasons unevenly from late 2009 to early 2012, while the ALOS/PALSAR data cover only winter.

All the satellite-derived velocities are plotted against the mean GPS velocities over the corresponding period in Fig. 11. The comparison of velocities derived from the ALOS/PALSAR satellite data is summarized in Table 2, while Table 3 shows comparison of velocities of the aggregate winter velocity maps. Finally, the comparison to the TerraSAR-X-derived data is given in Table 4. The latter also includes the number of the TerraSAR-X/Tandem-X orbit for 
Table 2. Comparison of ice velocities derived by GEUS from ALOS/PALSAR satellite radar imagery and ice velocities from GPS measurements. Start and end dates refer to the time window between image acquisitions. Ice velocities are given in $\mathrm{m} \mathrm{yr}^{-1}$, latitudes and longitudes in decimal degrees N and W, respectively, using the World Geodetic System 1984 (WGS84).

\begin{tabular}{ccccccccc}
\hline Station & Radar Proc. & Start date & End date & Mean Longitude & Mean Latitude & V_Radar & V_GPS Mean & V_GPS Stdev \\
\hline KNS_2 & GEUS & $28-09-2009$ & $13-02-2010$ & 64.165675 & -49.311810 & 1200 & 1179 \\
KNS_3 & GEUS & $28-09-2009$ & $13-02-2010$ & 64.124298 & -49.198995 & 603 & 606 \\
AVA_1 & GEUS & $20-11-2009$ & $05-01-2010$ & 70.128276 & -50.171919 & 598 & 491 & 32 \\
RNK_2 & GEUS & $20-11-2009$ & $05-01-2010$ & 71.774989 & -51.156946 & 1234 & 1502 & 23 \\
STO_1 & GEUS & $20-11-2009$ & $05-01-2010$ & 70.521379 & -50.066853 & 971 & 1015 & 22 \\
UPE_3 & GEUS & $12-12-2009$ & $27-01-2010$ & 72.806608 & -53.473952 & 532 & 537 & 321 \\
UPE_4 & GEUS & $12-12-2009$ & $27-01-2010$ & 72.792567 & -53.197504 & 256 & 304 & 161 \\
\hline
\end{tabular}

Table 3. Comparison of ice velocities derived by APL from aggregate velocity map based on TerraSAR-X satellite radar imagery and ice velocities from GPS measurements. Start and end dates refer to the time window between image acquisitions. Ice velocities are given in $\mathrm{m} \mathrm{yr}^{-1}$, latitudes and longitudes in decimal degrees $\mathrm{N}$ and W, respectively, using the World Geodetic System 1984 (WGS84).

\begin{tabular}{lcccccccc}
\hline Station & Radar Proc. & Start date & End date & Mean Longitude & Mean Latitude & V_Radar & V_GPS Mean & V_GPS Stdev \\
\hline SML_2 & APL & $15-11-2010$ & $15-04-2011$ & 61.070601 & -46.904749 & 248 & 183 & 30 \\
SML_3 & APL & $15-11-2010$ & $15-04-2011$ & 61.115331 & -46.878887 & 202 & 102 & 28 \\
KNS_1 & APL & $15-11-2010$ & $15-04-2011$ & 64.187201 & -49.385047 & 1313 & 1312 & 42 \\
KNS_2 & APL & $15-11-2010$ & $15-04-2011$ & 64.169895 & -49.337603 & 1115 & 1202 & 41 \\
KNS_3 & APL & $15-11-2010$ & $15-04-2011$ & 64.128595 & -49.208829 & 563 & 586 & 28 \\
RNK_2 & APL & $15-11-2010$ & $15-04-2011$ & 71.778729 & -51.206321 & 1652 & 1670 & 24 \\
\hline
\end{tabular}

the first image in the pair. The SAR velocities (V_Radar column) in Tables 2, 3 and 4 are obtained by nearest-neighbor interpolation at the mean GPS position within the acquisition time-frame (Start- and End-date columns). Temporally, they represent an average velocity over this time-span, which ranges from a minimum of 46 days for ALOS/PALSAR and of 11 days for TerraSAR-X.

The aim of the comparison is to find the difference between GPS-derived velocities and satellite-derived velocities, assuming that the former can be regarded as groundtruth. When deriving velocities from satellite radar imagery, we assume surface parallel flow, meaning that we reduce the three-dimensional problem by assuming the velocity vector lies in the local plane tangent to the surface. Since errors in this plane, which are slope-dependent, scale with velocity, we show the difference between the GPS-derived velocities and satellite-derived velocities in percentage. The errors also depend on correlation, which can be affected by speed. This however, is included in the error statistics. The absolute velocity differences can be deduced from the velocities listed in Tables 2, 3 and 4.

For the ice velocities from data set (1), which is based on ALOS/PALSAR, the mean difference from the in situ GPS measurements is $9.7 \%$, with RNK-2 at a maximum difference of $17.8 \%$. Excluding the two GPS records UPE-3 and UPE-4, due to their poorer quality, yields a mean difference of $8.4 \%$.

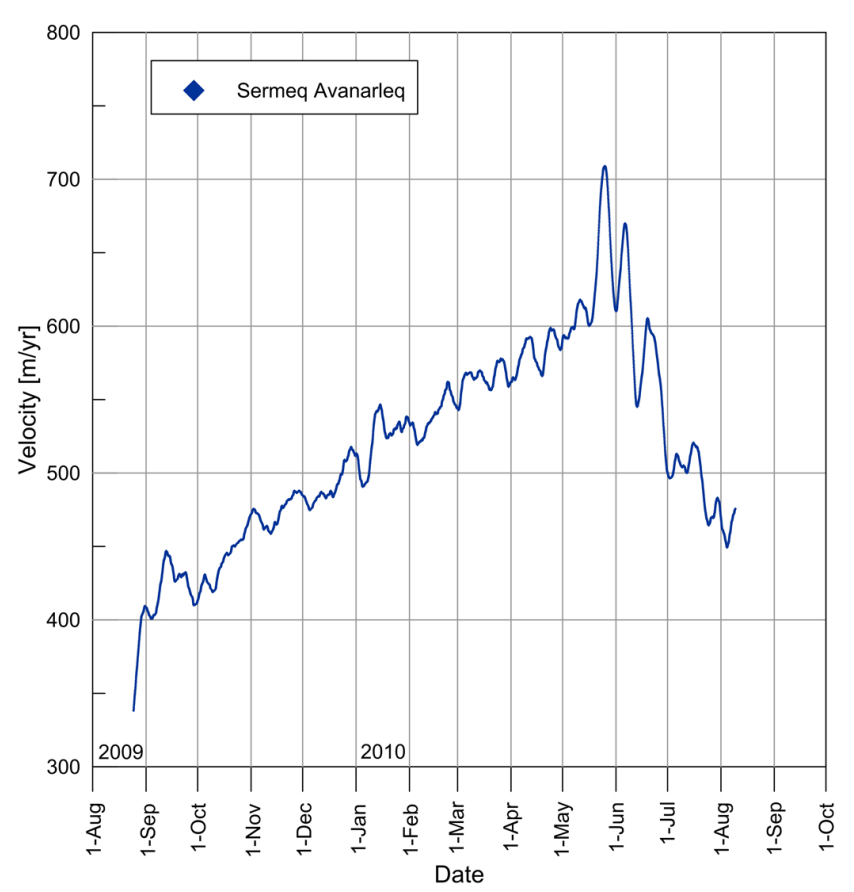

Figure 5. Sermeq Avanerleq 7-day averaged GPS velocities (see Fig. 1 and Table 1 for instrument position and operational period). 
Table 4. Comparison of ice velocities derived by APL from TerraSAR-X satellite radar imagery and ice velocities from GPS measurements. Ice velocities are given in $\mathrm{m} \mathrm{yr}^{-1}$, latitudes and longitudes in decimal degrees $\mathrm{N}$ and $\mathrm{W}$, respectively, using the World Geodetic System 1984 (WGS84).

\begin{tabular}{|c|c|c|c|c|c|c|c|c|c|}
\hline Station & Orbit \# & Start date & End_date & $\begin{array}{c}\text { Mean } \\
\text { Longitude }\end{array}$ & $\begin{array}{c}\text { Mean } \\
\text { Latitude }\end{array}$ & V_Radar & $\begin{array}{c}\text { V_Radar } \\
\text { Error }\end{array}$ & $\begin{array}{c}\text { V_GPS } \\
\text { Mean }\end{array}$ & $\begin{array}{c}\text { V_GPS } \\
\text { Stdev }\end{array}$ \\
\hline KNS_2 & 14625 & 02-02-2010 & $13-02-2010$ & 64.166383 & -49.315747 & 1236 & 3.172 & 1219 & 30 \\
\hline KNS_3 & 14625 & 02-02-2010 & $13-02-2010$ & 64.124921 & -49.200635 & 632 & 3.78 & 624 & 20 \\
\hline KNS_2 & 15794 & 20-04-2010 & 01-05-2010 & 64.167204 & -49.320707 & 1239 & 4.364 & 1238 & 18 \\
\hline KNS_3 & 15794 & 20-04-2010 & 01-05-2010 & 64.125695 & -49.202657 & 625 & 4.678 & 629 & 22 \\
\hline KNS_1 & 17798 & $30-08-2010$ & $10-09-2010$ & 64.184214 & -49.377314 & 1152 & 5.112 & 1129 & 53 \\
\hline KNS_2 & 17798 & $30-08-2010$ & $10-09-2010$ & 64.168539 & -49.328785 & 998 & 3.471 & 989 & 53 \\
\hline KNS_3 & 17798 & $30-08-2010$ & $10-09-2010$ & 64.127243 & -49.205514 & 456 & 3.174 & 459 & 48 \\
\hline KNS-1 & 18967 & $15-11-2010$ & $26-11-2010$ & 64.185691 & -49.381282 & 1260 & 3.484 & 1264 & 24 \\
\hline KNS-2 & 18967 & $15-11-2010$ & $26-11-2010$ & 64.169228 & -49.333183 & 1136 & 4.505 & 1140 & 21 \\
\hline KNS-3 & 18967 & $15-11-2010$ & $26-11-2010$ & 64.127909 & -49.207175 & 557 & 2.124 & 568 & 21 \\
\hline KNS_1 & 21472 & 29-04-2011 & $10-05-2011$ & 64.189388 & -49.390169 & 1383 & 3.412 & 1381 & 35 \\
\hline KNS_2 & 21472 & 29-04-2011 & $10-05-2011$ & 64.170830 & -49.343816 & 1233 & 3.111 & 1254 & 30 \\
\hline KNS_3 & 21472 & 29-04-2011 & $10-05-2011$ & 64.129563 & -49.211123 & 610 & 2.067 & 615 & 38 \\
\hline KNS_1 & 22641 & $15-07-2011$ & 26-07-2011 & 64.191467 & -49.394483 & 1458 & 2.158 & 1505 & 28 \\
\hline KNS_2 & 22641 & $15-07-2011$ & 26-07-2011 & 64.171663 & -49.349189 & 1282 & 3.601 & 1267 & 30 \\
\hline KNS_3 & 22641 & $15-07-2011$ & 26-07-2011 & 64.130424 & -49.213112 & 604 & 2.117 & 595 & 29 \\
\hline STO_1 & 14625 & 02-02-2010 & $13-02-2010$ & 70.520161 & -50.069092 & 1049 & 3.611 & 1048 & 25 \\
\hline STO_1 & 15961 & 01-05-2010 & $12-05-2010$ & 70.518190 & -50.072692 & 1075 & 4.939 & 1086 & 26 \\
\hline STO_A & 18633 & 24-10-2010 & $15-11-2010$ & 70.448565 & -50.354504 & 1852 & 3.168 & 1849 & 29 \\
\hline STO_A & 18967 & $15-11-2010$ & $26-11-2010$ & 70.448108 & -50.356295 & 1872 & 3.46 & 1871 & 17 \\
\hline STO_A & 21472 & 29-04-2011 & $10-05-2011$ & 70.442454 & -50.373692 & 2110 & 3.999 & 2132 & 20 \\
\hline STO_A & 22641 & $15-07-2011$ & 26-07-2011 & 70.439183 & -50.381022 & 2126 & 2.624 & 2073 & 99 \\
\hline STO_A & 24478 & 13-11-2011 & 24-11-2011 & 70.434248 & -50.390666 & 2076 & 2.201 & 1996 & 137 \\
\hline STO_A & 25814 & 09-02-2012 & $20-02-2012$ & 70.430536 & -50.397347 & 2188 & 1.88 & 2179 & 24 \\
\hline RNK_2 & 13220 & 01-11-2009 & $12-11-2009$ & 71.774660 & -51.152789 & 1484 & 4.23 & 1428 & 18 \\
\hline RNK_2 & 15892 & 26-04-2010 & 07-05-2010 & 71.776240 & -51.173033 & 1528 & 6.98 & 1537 & 27 \\
\hline RNK_2 & 16894 & 01-07-2010 & $12-07-2010$ & 71.776873 & -51.180892 & 1581 & 5.26 & 1577 & 16 \\
\hline RNK_2 & 17729 & $25-08-2010$ & 05-09-2010 & 71.777427 & -51.187745 & 1582 & 5.25 & 1609 & 30 \\
\hline RNK_2 & 2335 & 21-11-2010 & 02-12-2010 & 71.778228 & -51.198655 & 1571 & 4.51 & 1656 & 24 \\
\hline RNK_2 & 21403 & 24-04-2011 & $05-05-2011$ & 71.779506 & -51.218457 & 1687 & 3.14 & 1695 & 25 \\
\hline SML_2 & 2578 & $07-12-2010$ & $18-12-2010$ & 61.070813 & -46.904721 & 238 & 7.50 & 215 & 22 \\
\hline SML_3 & 2578 & $07-12-2010$ & $18-12-2010$ & 61.115448 & -46.878844 & 153 & 111.28 & 119 & 22 \\
\hline
\end{tabular}

For the aggregate velocities of data set (2) the mean difference is $9.5 \%$, excluding SML-3 from the comparison, as it is considered to be too poor quality in the velocity map (note the large formal error stated for this location in Table 4). Excluding also SML-2 would bring the mean difference down to just $3.1 \%$. Note that the comparison of data set (2) to the GPS velocities cannot be used to assess the accuracy of the velocity mapping method, only the error that a user might need to take into account if assuming that the map represents the mean velocity over the time period of the aggregate velocity map.

For the ice velocity data set (3) based on TerraSAR-X the mean difference is $1.5 \%$, when excluding SML-3 as discussed above. SML-2 has the maximum difference of $10.7 \%$. Excluding both SML-2 and SML-3 yields a mean difference of $1.2 \%$, while RNK-2 (orbit 2335) would then have the maximum difference of $5.1 \%$. The better agreement is an expected consequence of the higher spatial and temporal resolution of the TerraSAR-X data and is consistent with the level of error $(<3 \%)$ for the algorithms that produced them (Joughin, 2002).

\section{Discussion}

The velocity records presented generally exhibit a pattern of significant seasonal variation, peaking in spring, with higher velocities and more pronounced variation closer to the glacier fronts. The character and strength of the seasonal variation varies among the glaciers studied. An important aspect is the rapid deceleration of many of the glaciers during the melt season, similar to the one found by Howat et al. (2010) for six marine-terminating outlet glaciers in the Uummannaq region of West Greenland, of which Rink and Store Glacier are also included in this study. Howat 


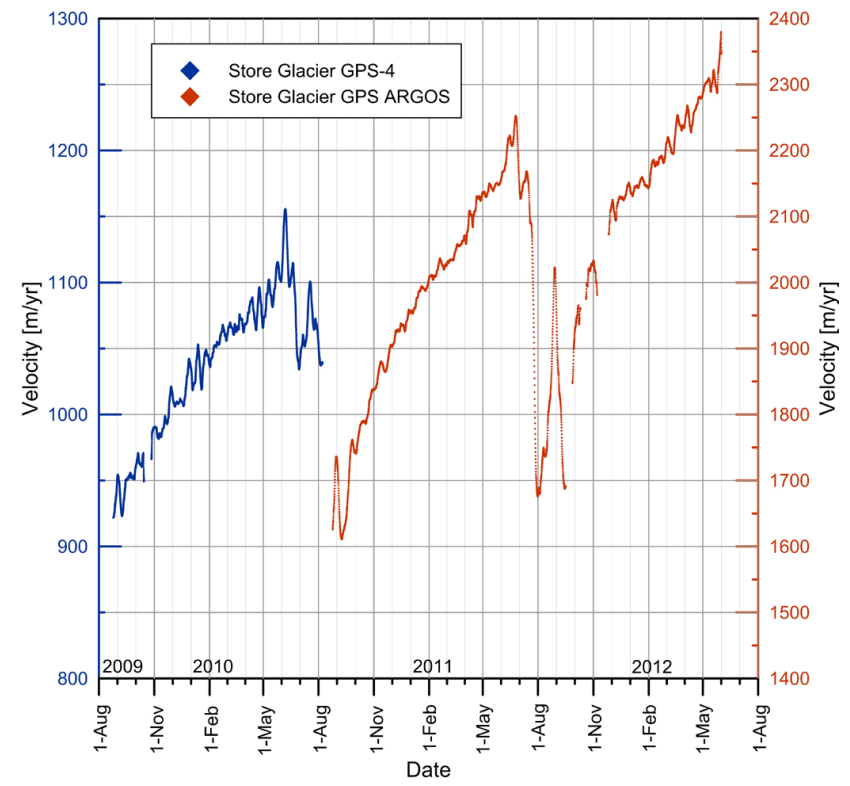

Figure 6. Store Glacier 7-day averaged GPS velocities (see Fig. 1 and Table 1 for instrument position and operational period). Note the different scales for the two GPS velocity records.

et al. (2010) produced velocity time series from featuretracking of optical satellite images (Landsat 7) close to the calving front. They detected significant summer deceleration of Store Glacier only in 2002 and 2005, coinciding with meltwater lake drainage events, whereas our data seems to indicate that this pattern has occurred at least in 2010 and 2011 and possibly also in 2012, where the data series stop short just prior to the expected onset of deceleration.

The GPS velocity data are influenced by the advection of the instrument down-glacier towards faster-flowing parts nearer the front. This was the case for data from the Rink Glacier (Fig. 7), where we examined the effect by comparing it to a velocity gradient on a satellite-derived velocity map (not shown). The check confirmed that the background increase in velocity was largely due to the GPS advecting into a faster part of the glacier. This spatial impact on a data series that has as a primary goal to detect temporal variability can thus be quantified and removed using satellite-derived velocities. However, most of the GPS data records presented here are only mildly influenced by this effect, as is evident when comparing multi-year data records (e.g. Figs. 3 and 4). Yet the advection problem makes it difficult to compare to the results of Howat et al. (2010) for Rink Glacier.

The observed seasonal variation in velocity has important implications for satellite-derived velocity mapping and its application in the mass budget method. The results show that the velocities of the marine-terminating outlet glaciers can vary dramatically over short time spans, particularly during the summer season, implying that velocities derived from specific time windows between image acquisitions will

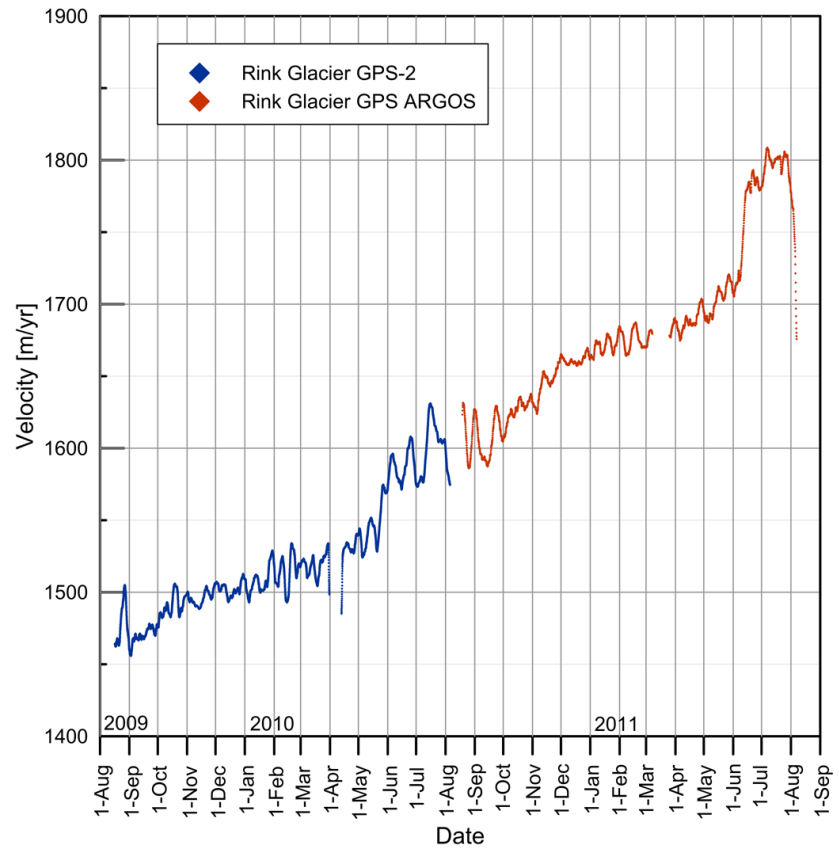

Figure 7. Rink Glacier 7-day averaged GPS velocities (see Fig. 1 and Table 1 for instrument position and operational period). The ARGOS GPS was deployed at the retrieval position of GPS-2. Note the effect of the GPS instruments being advected towards faster moving parts of the glacier.

not necessarily capture the variability. Inferring the dynamic mass loss from satellite-derived velocity maps often requires the assumption that the velocities obtained represent a mean value over a longer period of time due to limitations on the frequency with which the data are collected. The velocity maps are, however, based on image-comparison techniques that only delivers velocities over the period in between two image acquisitions, and cannot be considered representative for a shorter or longer time span.

\section{Conclusions}

The continuous in situ GPS data presented here were acquired on a range of types of marine-terminating outlet glaciers in Greenland. Common to all the observed glacier velocity records is a pronounced seasonal variation, with an early melt season maximum. For some glaciers, this maximum is followed by a minimum in late summer, for others by a return to a background velocity. Generally, the onset of the acceleration comes later for northern glaciers (Figs. 9 and 10). The GPS records spanning several years (Figs. 3, 4, 6 and 7) show that each individual glacier tends to reproduce its own pattern of seasonal velocity variation.

The GPS velocities compare well with velocity maps derived from different satellite data and by different processing chains, supporting the validity of the velocity mapping technique, even over fast-flowing outlet glaciers. The comparison 


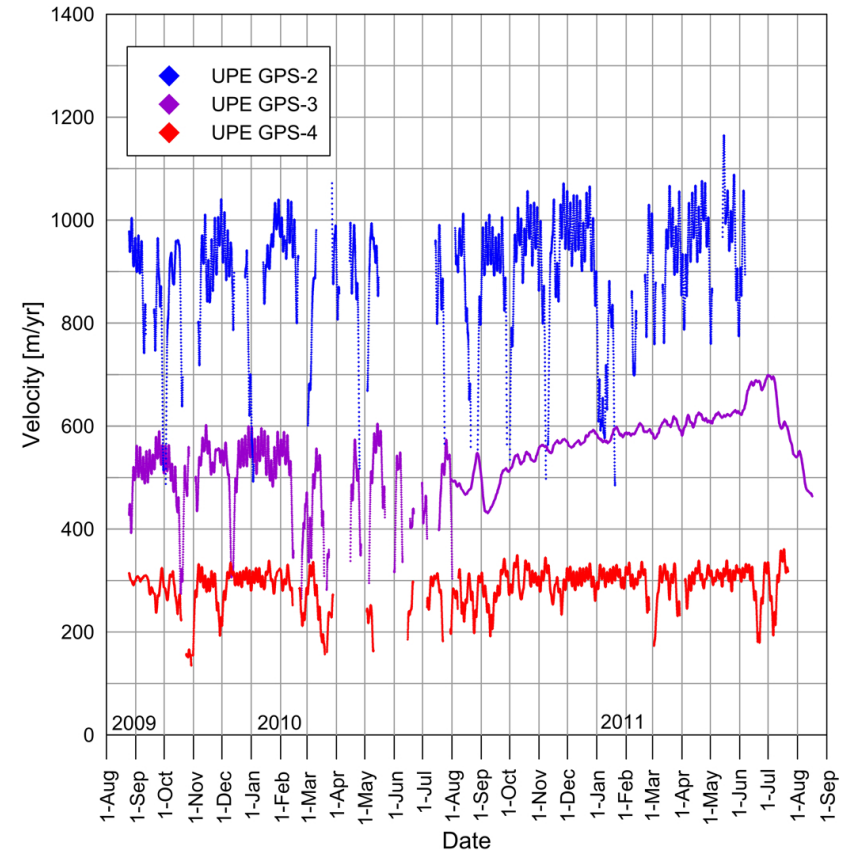

Figure 8. Upernavik Glacier 7-day averaged GPS velocities (see Fig. 1 and Table 1 for instrument position and operational period). The generally poor quality of the averaged velocities is due to data damage during logger extraction, causing a necessary relaxation of the averaging criteria used. The data are still useful for obtaining a general idea of the velocities, however.

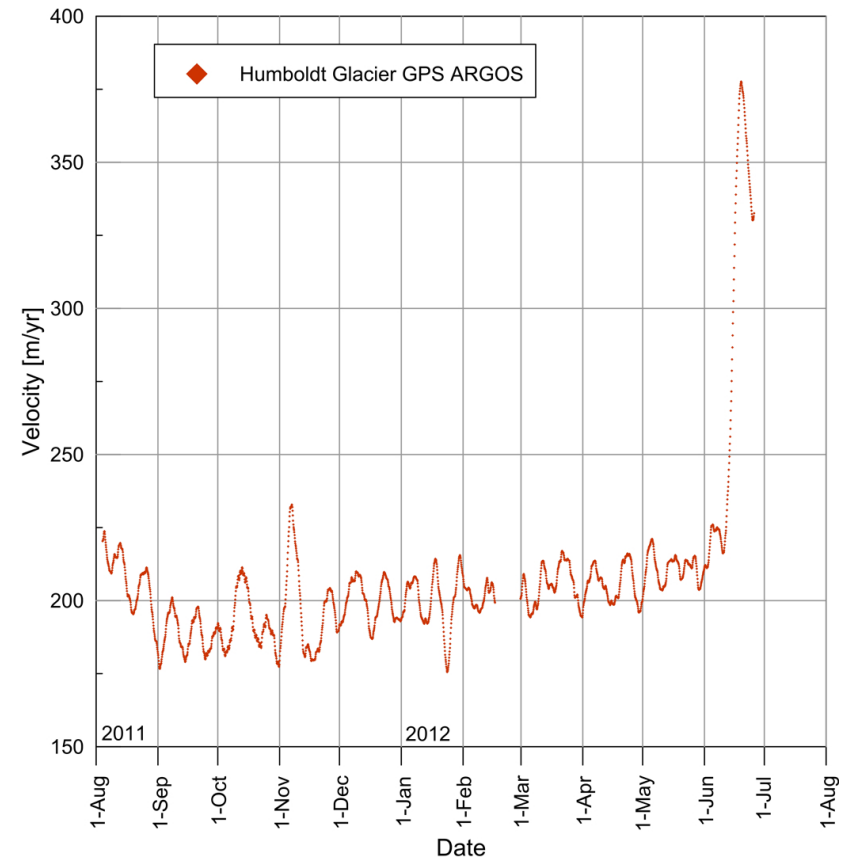

Figure 9. Humboldt Glacier 7-day averaged GPS velocities (see Fig. 1 and Table 1 for instrument position and operational period).

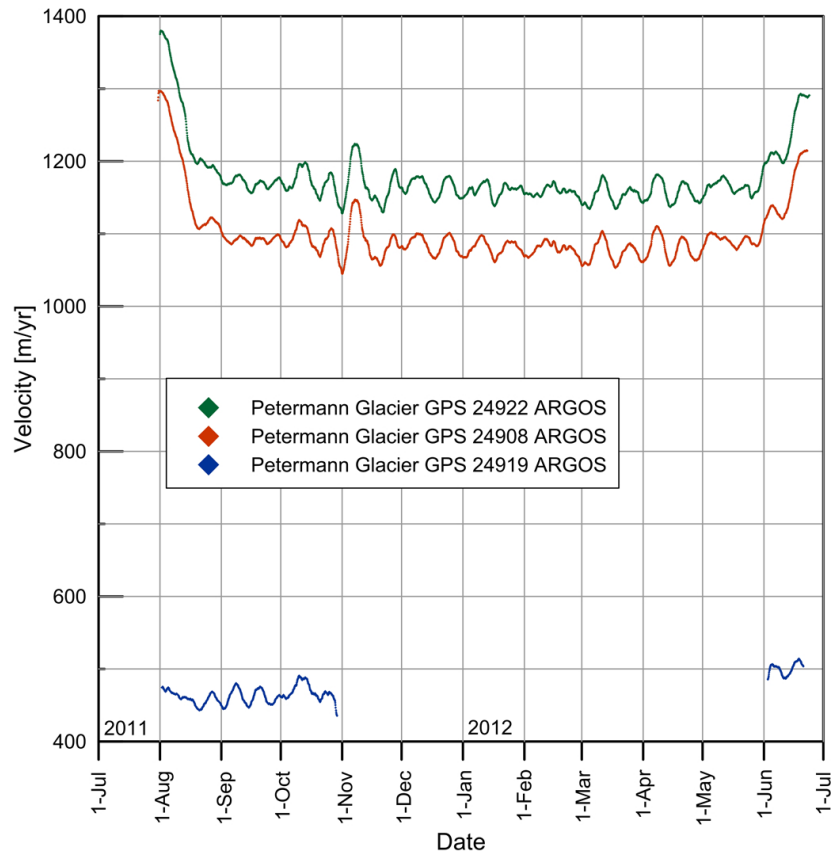

Figure 10. Petermann Glacier 7-day averaged GPS velocities (see Fig. 1 and Table 1 for instrument position and operational period).

improves with higher resolution and shorter time span of the satellite-derived velocities, suggesting that the in situ GPS data presented are indeed useful for ground-truthing the satellite products, despite being single-frequency stand-alone instruments.

The seasonal variability in the velocities documented in the GPS data also calls for caution when employing the satellite-derived velocity maps to infer discharge from the ice sheet, as the latter will only rarely capture the full range of variability. As previously discussed by Moon et al. (2012) the velocity of an outlet glacier cannot be considered as representing a larger region, as differences between neighboring glaciers can be large. It is therefore not straightforward to combine the temporal qualities of the GPS velocity records from a few glaciers with the regional spatial coverage of the satellite-derived velocity maps. Yet the GPS velocity records might be taken as an indication of how well a given velocity map represents the period for which it is used to calculate ice discharge.

To sum up, we have presented 17 separate records of velocity derived from GPS acquired on eight marineterminating outlet glaciers from the Greenland ice sheet, over varying parts of 2009-2012. These records are useful as ground-truthing for ongoing velocity mapping efforts, but also for determining how well the velocity maps represent the periods outside the image acquisition windows. Finally, the GPS velocity records makes it possible to validate and calibrate current modeling efforts investigating the coupling between the ice sheet and the ocean/climate and thus serve 


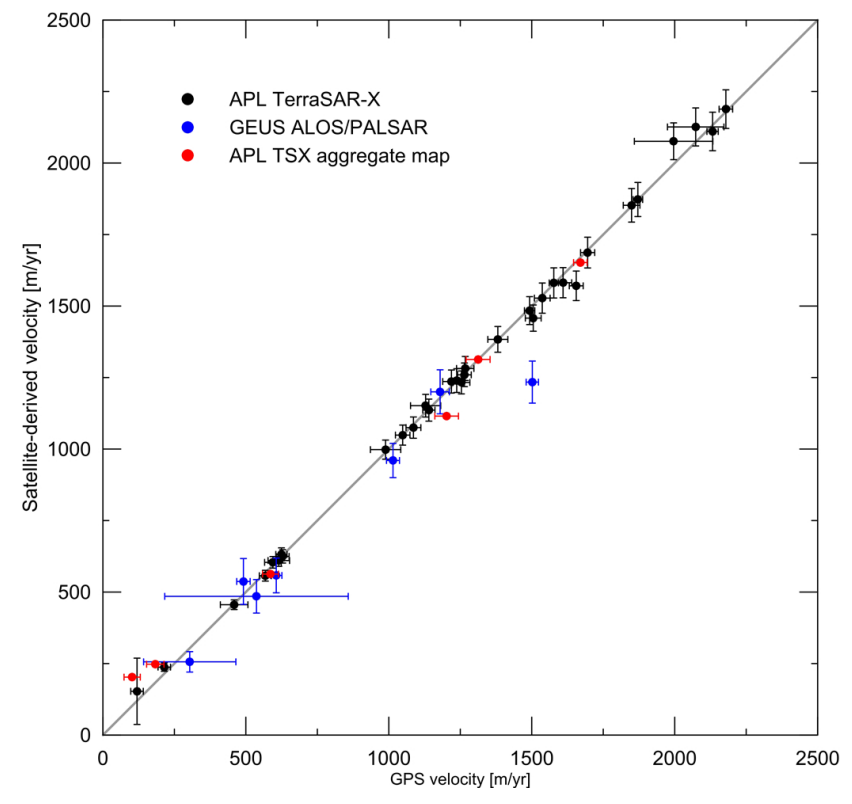

Figure 11. Comparison of satellite-derived velocities with GPS velocities. Horizontal error bars denote the standard deviation of the 7-day averaged GPS velocities in the period of the acquisition window. The vertical error bars denote the formal error from the processing added to a $3 \%$ maximum error due to slope-dependent effects. The black point with the lowest velocity (and largest vertical error bar) is SML-3, which originates from the ragged edge of a velocity map over Sermilik Bræ as discussed in the text.

to improve our understanding of the dynamic mass loss from the Greenland ice sheet.

Acknowledgements. The majority of this work was supported by funding from the ice2sea programme from the European Union 7th Framework Programme, grant no. 226375, ice2sea contribution number 130 . The study also received partial financial support from the Danish Energy Agency through the Programme for Monitoring of the Greenland Ice Sheet (PROMICE) as well as from the Danish Agency for Science, Technology and Innovation through project no. GCRC6509 of the Greenland Climate Research Centre. J. E. Box was supported by US National Science Foundation grant AGS-1061864, managed by D. J. Verardo and The Ohio State University's Climate Water Carbon initiative, managed by D. E. Alsdorf. A. Hubbard acknowledges Greenpeace and the tireless crews of M/V Arctic Sunrise and S/V Gambo for providing field logistics for Petermann, Humboldt, Upernavik, Store \& Rink Glacier deployments and recoveries and the Aberystwyth University Research Fund \& NERC Grant NE/G005796/1 for field/logistical support. Published with the permission of the Geological Survey of Denmark and Greenland.

Edited by: O. Eisen

\section{References}

Ahlstrøm, A. P., Van As, D., Citterio, M., Andersen, S. B., Nick, F. M., Gravesen, P., Edelvang, K., Fausto, R., Andersen, M. L., Kristensen, S. S., Christensen, E. L., Boncori, J. P. M., Dall, J., Forsberg, R., Stenseng, L., Hanson, S., and Petersen, D.: Final report for the establishment phase of Programme for Monitoring of the Greenland Ice Sheet, Danmarks og Grønlands Geologiske Undersøgelse Rapport 2011/18, 2011.

Ahn, Y. and Box, J. E.: Glacier velocities from time lapse photos: technique development and first results from the Extreme Ice Survey (EIS) in Greenland, J. Glaciol., 56, 723-734, 2010.

Andresen, C. S., Straneo, F., Hvid Ribergaard, M., Bjørk, A. A., Andersen, T. J., Kuijpers, A., Nørgaard-Pedersen, N., Kjær, K. H., Schjøth, F., Weckström, K., and Ahlstrøm, A. P.: Rapid response of Helheim Glacier in Greenland to climate variability over the past century, Nat. Geosci., 5, 37-41, doi:10.1038/ngeo1349, 2011.

Bevan, S. L., Luckman, A. J., and Murray, T.: Glacier dynamics over the last quarter of a century at Helheim, Kangerdlugssuaq and 14 other major Greenland outlet glaciers, The Cryosphere, 6, 923-937, doi:10.5194/tc-6-923-2012, 2012.

Bevis, M., Wahr, J., Khan, S. A., Madsen, F. B., Brown, A., Willis, M., Kendrick, E., Knudsen, P., Box, J. E., van Dam, T., Caccamise II, D. J., Johns, B., Nylen, T., Abbott, R., White, S., Miner, J., Forsberg, R., Zhou, H., Wang, J., Wilson, T., Bromwich, D., and Francis, O.: Bedrock displacements in Greenland manifest ice mass variations, climate cycles and climate change, P. Natl. Acad. Sci., 109, 11944-11948, doi:10.1073/pnas.1204664109, 2012.

Bjørk, A. A., Kjær, K. H., Korsgaard, N. J., Khan, S. A., Kjeldsen, K. K., Andresen, C. S., Box, J. E., Larsen, N. K., and Funder, S.: An aerial view of 80 years of climate-related glacier fluctuations in southeast Greenland, Nat. Geosci., 5, 427-432, doi:10.1038/ngeo1481, 2012.

Den Ouden, M. A. G., Reijmer, C. H., Pohjola, V., Van de Wal, R. S. W., Oerlemans, J., and Boot, W.: Stand-alone single-frequency GPS ice velocity observations on Nordenskiöldbreen, Svalbard, The Cryosphere, 4, 593-604, doi:10.5194/tc-4-593-2010, 2010.

Dunse, T., Schuler, T. V., Hagen, J. O., and Reijmer, C. H.: Seasonal speed-up of two outlet glaciers of Austfonna, Svalbard, inferred from continuous GPS measurements, The Cryosphere, 6, 453466, doi:10.5194/tc-6-453-2012, 2012.

Ettema, J., Van den Broeke, M. R., Van Meijgaard, E., Van de Berg, W. J., Box, J. E., and Steffen, K.: Climate of the Greenland ice sheet using a high-resolution climate model - Part 1: Evaluation, The Cryosphere, 4, 511-527, doi:10.5194/tc-4-511-2010, 2010.

Howat, I. M., Box, J. E., Ahn, Y., Herrington, A., and McFadden, E. M.: Seasonal variability in the dynamics of marine-terminating outlet glaciers in Greenland, J. Glaciol., 56, 601-613, 2010.

IPCC: Climate Change 2007: The Physical Science Basis. Contribution of Working Group I to the Fourth Assessment Report of the Intergovernmental Panel on Climate Change, edited by: Solomon, S., Qin, D., Manning, M., Chen, Z., Marquis, M., Averyt, K. B., Tignor, M., and Miller, H. L., Cambridge University Press, Cambridge, United Kingdom and New York, NY, USA, 996 pp., 2007.

Joughin, I.: Ice-Sheet Velocity Mapping: A Combined Interferometric and Speckle-Tracking Approach, Ann. Glaciol. 34, 195-201, 
doi:10.3189/172756402781817978, 2002.

Joughin, I., Das, S. B., King, M. A., Smith, B. E., Howat, I. M., and Moon, T.: Seasonal Speedup Along the Western Flank of the Greenland Ice Sheet, Science, 320, 781-783, 2008.

Joughin, I., Smith, B. E., Howat, I. M., Scambos, T., and Moon, T.: Greenland flow variability from ice-sheet-wide velocity mapping, J. Glaciol., 56, 415-430, 2010.

Joughin, I., Smith, B. E., Howat, I. M., Floricioiu, D., Alley, R. B., Truffer, M., and Fahnestock, M.: Seasonal to decadal scale variations in the surface velocity of Jakobshavn Isbrae, Greenland: Observation and model-based analysis, J. Geophys. Res., 117, F02030, doi:10.1029/2011JF002110, 2012.

Merryman Boncori, J. P., Dall, J., Ahlstrøm, A. P., and Andersen, S. B.: Validation and operational measurements with SUSIE - a SAR ice motion processing chain developed within PROMICE (Programme for the Monitoring of the Greenland Ice-sheet), in: Proc. ESA Living Planet Symposium, Bergen, Norway, SP-686, 2010.

Moon, T., Joughin, I., Smith, B., and Howat, I.: 21st-Century Evolution of Greenland Outlet Glacier Velocities, Science, 336, 576578, doi:10.1126/science.1219985, 2012.

Nick, F. M., Luckman, A., Vieli, A., Van der Veen, C. J., Van As, D., Van de Wal, R. S. W., Pattyn, F., Hubbard, A. L., and Floricioiu, D.: The response of Petermann Glacier, Greenland, to large calving events, and its future stability in the context of atmospheric and oceanic warming, J. Glaciol., 58, 229-239, doi:10.3189/2012JoG11J242, 2012.

Press, W. H., Teukolsky, S. A., Vetterling, W. T., and Flannery, B. P.: Numerical Recipes in FORTRAN: the art of scientific computing, 2nd Edn., Cambridge University Press, Cambridge, 1992.

Price, S. F., Payne, A. J., Howat, I. M., and Smith, B. E.: Committed sea-level rise for the next century from Greenland ice sheet dynamics during the past decade, P. Natl. Acad. Sci., 108, 89788983, doi:10.1073/pnas.1017313108, 2011.
Pritchard, H. D., Arthern, R. J., Vaughan, D. G., and Edwards, L. A.: Extensive dynamic thinning on the margins of the Greenland and Antarctic ice sheets, Nature, 461, 971-975, doi:10.1038/nature08471, 2009.

Rignot, E. and Kanagaratnam, P.: Changes in the Velocity Structure of the Greenland Ice Sheet, Science, 311, 986-990, doi:10.1126/science.1121381, 2006.

Rignot, E., Box, J. E., Burgess, E., and Hanna, E.: Mass balance of the Greenland ice sheet from 1958 to 2007 , Geophys. Res. Lett., 35, L20502, doi:10.1029/2008GL035417, 2008.

Rignot, E., Velicogna, I., Van den Broeke, M. R., Monaghan, A., and Lenaerts, J.: Acceleration of the contribution of the Greenland and Antarctic ice sheets to sea level rise, Geophys. Res. Lett., 38, L05503, doi:10.1029/2011GL046583, 2011.

Sørensen, L. S., Simonsen, S. B., Nielsen, K., Lucas-Picher, P., Spada, G., Adalgeirsdottir, G., Forsberg, R., and Hvidberg, C. S.: Mass balance of the Greenland ice sheet (2003-2008) from ICESat data - the impact of interpolation, sampling and firn density, The Cryosphere, 5, 173-186, doi:10.5194/tc-5-173-2011, 2011.

Van de Wal, R. S. W., Boot, W., Van den Broeke, M. R., Smeets, C. J. P. P., Reijmer, C. H., Donker, J. J. A., and Oerlemans, J.: Large and Rapid Melt-Induced Velocity Changes in the Ablation Zone of the Greenland Ice Sheet, Science, 321, 111-113, doi:10.1126/science.1158540, 2008.

Van den Broeke, M., Bamber, J., Ettema, J., Rignot, E., Schrama, E., Van de Berg, W. J., Van Meijgaard, E., Velicogna, I., and Wouters, B.: Partitioning recent Greenland mass loss, Science, 326, 984-986, doi:10.1126/science.1178176, 2009.

Vieli, A. and Nick, F. M.: Understanding and modeling rapid dynamic changes of tidewater outlet glaciers: issues and implications, Surv. Geophys., 32, 437-458, doi:10.1007/s10712-0119132-4, 2011. 